\title{
Ocular bobbing with extra-axial haematoma of posterior fossa
}

\author{
PASQUALE F. FINELLI AND WILLIAM J. McENTEE \\ From the Neurology Service, Veterans Administration Hospital, and the Subsection of Neurology, Brown \\ University, Division of Biological and Medical Sciences, Providence, Rhode Island, USA
}

SUMMARY A patient with a subarachnoid haematoma anterior to the brain stem demonstrated $\frac{\overline{\bar{c}}}{\sqrt{5}}$ 'typical' ocular bobbing. The absence of CNS parenchymal involvement is distinct from previouslyळ described posterior fossa lesions associated with this particular eye movement disorder.

Since Fisher's $(1961,1964)$ original descriptions of the phenomenon of ocular bobbing, subsequent reports (Daroff and Waldman, 1965; Hameroff et al., 1969; Nelson and Johnston, 1970; Susac et al., 1970) have confirmed his original observations, and have led to a classification of this ocular sign into three groups: typical, atypical, and monocular bobbing (Susac et al., 1970). Typical ocular bobbing is usually associated with intrapontine disease, although it has also been observed in cases of cerebellar haemorrhage with secondary pontine compression.

This report is concerned with typical ocular bobbing in a patient who, at necropsy, was found to have an extra-axial haematoma anterior to the brain stem. The parenchyma of the brain stem and cerebellum were spared.

\section{Case report}

A 73 year old white male was in his usual state of health until the evening of admission when he suddenly slumped forward unresponsive in his chair. Significant past history included arteriosclerotic heart disease and hypertension. Physical examination on the evening of admission revealed an elderly white male who was lethargic but responded to pain and answered simple questions appropriately. There were no signs of trauma about the head. Blood pressure on admission was $180 / 110 \mathrm{mmHg}$, pulse was 60 per minute and regular, respirations were rhythmical at 14 per minute, and the patient was afebrile. Cardiac exam revealed a grade III (out of VI) systolic murmur along the left sternal border. Neurological examina-

Address for reprint requests: Dr P. F. Finelli, VA Hospital, Davis Park, Providence, Rhode Island 02908, USA.

Accepted 10 November 1976 tion showed a moderate degree of nuchal rigidity. and bruits were present over both carotid arteries. $\overline{\bar{z}}$ The pupils were equal, round, and reacted to light $?$ Examination of the optic fundi showed multiple ${ }^{+}$ retinal haemorrhages bilaterally. No nystagmus was. elicited; however, the patient could not move eithe eye horizontally. No facial weakness was observea The patient moved all four extremities spontaneous $\$$ and the deep tendon reflexes were $2+$ and symmetical throughout. He responded to pin prick stimulation appropriately throughout. The plantar responses were extensor bilaterally. Laboratory results क्षेत् admission were as follows. White blood cell coumt $\checkmark$ was $20,000 / \mathrm{mm}^{3}$ with 66 per cent polymorphonuclear leucocytes. Blood sugar concentration was 11.1 ? $\mathrm{mmol} / \mathrm{l}$, and serum electrolytes were within normal limits. Blood urea was $8.6 \mathrm{mmol} / \mathrm{l}$. On lumbar punc-@ ture the opening pressure was $250 \mathrm{~mm}$ of water. The CSF was grossly bloody, and the supernatant was xanthochromic on immediate centrifugation. Theō cell count of CSF produced 500,000 red cells and 3 1,300 white cells per cubic millimetre, 84 per cent of the white cells being lymphocytes. The protein level was $17 \mathrm{~g} / \mathrm{l}$, glucose was $2.94 \mathrm{mmol} / \mathrm{l}$, and no bacteria were seen on the Gram stained smear. Four bloodo cultures revealed no growth. Chest and skull radiographs were normal, as was the radioisotope brain scan. The electrocardiogram showed left ventricularô hypertrophy with strain.

The day after admission the patient exhibited only을 the ability to blink his eyes and to squeeze fingers on $>$ command. The pupils were miotic and there was a을. marked increase in muscle tone bilaterally, more pronounced on the left side. At this time ocular bob- - T bing was observed, and this consisted of spontaneous $N$ downward jerks of both eyes which slowly returned to N the mid position. The eyes could not be deviatedo 
horizontally by either doll's eye manoeuvres or ice water caloric testing. On the third day in hospital the patient became febrile. This was thought to be secondary to aspiration pneumonia. Increasing muscular rigidity with decerebrate posturing followed. Angiography of the posterior fossa was performed via a right brachial injection, and no abnormalities were observed. The ocular bobbing persisted and the patient's condition remained grave without improvement. The patient died on his eighth day in hospital.

\section{Neuropathology}

External examination of the brain showed an extensive subarachnoid haematoma covering the ventral aspect of the brain stem (Fig. 1). The vertebral and basilar arteries were entirely encased within the haematoma. The vessels were dissected and carefully examined for the presence of a ruptured berry aneurysm but none was found.

Multiple sections of the brain revealed the CNS parenchyma to be intact and showed no source of intraparenchymal bleeding. The fourth ventricle, which was not significantly enlarged or distorted, contained a small amount of blood. Histological sections showed that the midbrain, pons, and medulla were intact (Fig. 2). The blood vessels showed minimal atherosclerotic changes. A localised collection of thin-walled blood vessels, both arteries and veins, was identified within the subarachnoid space between the pyramids of the medulla (Fig. 3). This was thought to represent a small arteriovenous malformation that may have been the source of bleeding in this patient.
Discussion

Bosch et al (1975) emphasised the nonlocalising value of ocular bobbing in an effort to dispel the notion put forward by Nelson and Johnston (1970) that typical ocular bobbing should not discourage the search for a treatable lesion. Our patient was studied to exclude

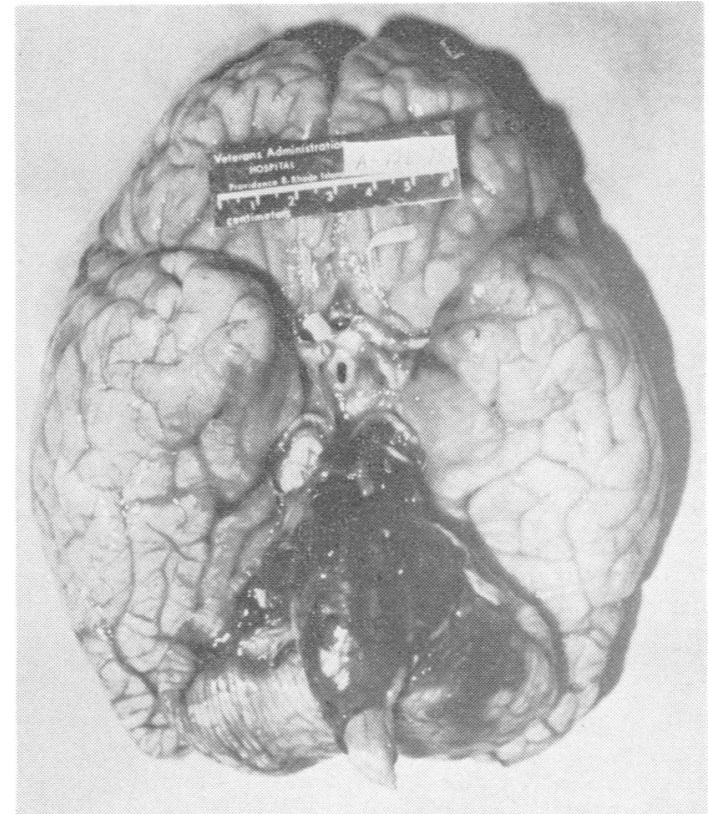

Fig. 1 Gross specimen showing extent of subarachnoid haematoma.

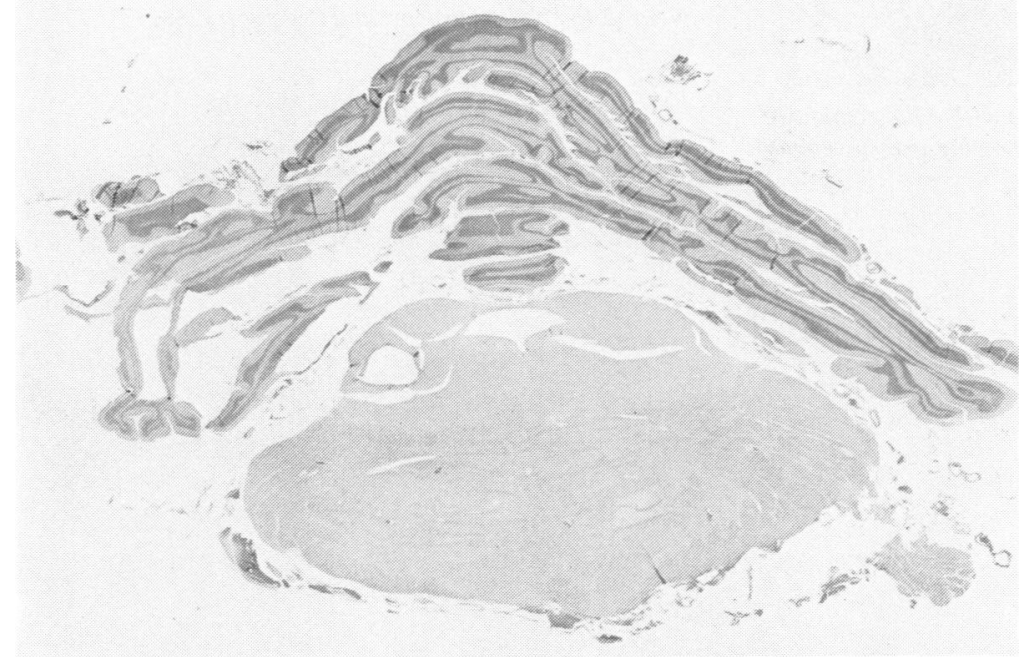

Fig. 2 Cross-section showing intact pons and cerebellum. 


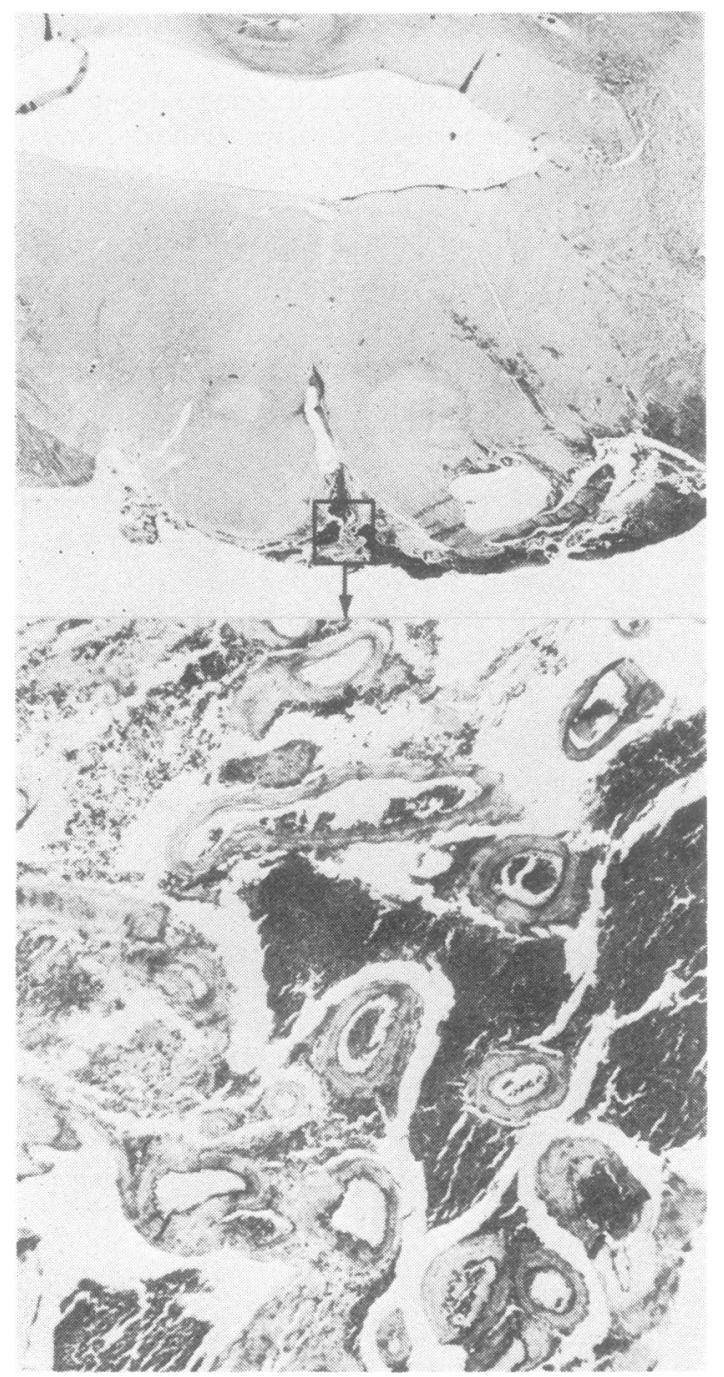

Fig. 3 Cross-section of medulla (top) with enlargement of area between the pyramids (bottom) showing arteriovenous malformation. the possibility of a cerebellar haemorrhage but the posterior fossa angiogram was completely normal.

One may speculate that the ocular bobbing in this case resulted from extrinsic pressure on the pons. However, the haematoma extended over almost the entire ventral surface of the brain stem. The rarity of a subarachnoid haematoma anterior to the brain stem may in part explain why this particular eye movement disorder has not been described previously with a lesion in this area.

All the cases of typical ocular bobbing reported to date have occurred in patients with either intrinsic pontine disease or cerebellar haemorrhage. To the best of our knowledge this is the only instance of typical ocular bobbing occurring with extraparenchymal disease of the brain stem or cerebellum.

\section{References}

Bosch, E. P., Kennedy, S. S., and Aschenbrener, C. A. (1975). Ocular bobbing: The myth of its localising value. Neurology (Minneap.), 25, 949-953.

Daroff, R. B. and Waldman, A. L. (1965). Ocular bobbing. Journal of Neurology, Neurosurgery, and Psychiatry, 28, 375-377.

Fisher, C. M. (1961). Clinical syndromes of cerebrap hemorrhage. In Houston Symposium on Pathogenesis o and Treatment of Cerebrovascular Disease. Edited byㅁㅇㅛ W. S. Fields, pp. 318-342. Charles C. Thomas: Spring field, Illinois.

Fisher, C. M. (1964). Ocular bobbing. Archives of Neuro $\log y$ (Chic.), 11, 543-546.

Hameroff, S. B., Garcia-Mullin, R., and Eckholdt, toㅡ․ (1969). Ocular bobbing. Archives of Ophthalmology, 82? 국 774-780.

Nelson, J. R., and Johnston, C. H. (1970). Ocular bobbing. Archives of Neurology (Chic.), 22, 348-356.

Susac, J. O., Hoyt, W. F., Daroff, R. B., and Lawrence, W. (1970). Clinical spectrum of ocular bobbing. Journal of Neurology, Neurosurgery, and Psychiatry, 33, 771-775. 